\title{
Fibro-adipogenesis in Injured Rotator Cuff Muscle
}

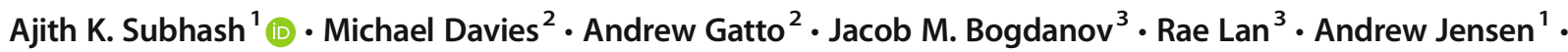 \\ Brian T. Feeley ${ }^{2} \cdot$ Frank A. Petrigliano $^{3}$
}

Accepted: 22 December 2021 / Published online: 8 January 2022

(C) The Author(s) 2022

\begin{abstract}
Purpose of Review Fibro-adipogenic progenitors were first characterized in 2010 and later found to contribute significantly to muscle regeneration and mediate degenerative changes in muscle following injury. These progenitors were also found to have an influence on the rotator cuff muscle's response to chronic injury which is defined by fibrosis accompanied by massive fatty degeneration. The purpose of this review is to highlight progenitor cells, their contribution to fibro-adipogenesis in rotator cuff tissue, and the factors influencing fibro-adipogenesis in this tissue.

Recent Findings Fibro-adipogenic progenitors are a key mediator of the fatty infiltration notably prevalent in rotator cuff injury. Relative to other muscle groups, the rotator cuff has relatively high rates of fibro-adipogenesis following massive chronic rotator cuff tears. This may be linked to the pre-injury density of fibro-adipogenic progenitors in muscle tissue affecting post-injury levels of fibro-adipogenesis. In addition, suprascapular nerve injury in rat models of rotator cuff tears has demonstrated worse, histologic, and biomechanical properties and lower healing rates of rotator cuff repairs. However, fatty infiltration in the rotator cuff following suprascapular nerve compression has been shown to be reversible following release of the nerve compression. Summary The fibro-adipogenic response to acute and chronic injury in rotator cuff tissue is determined by a complex array of factors including progenitor cell influence, transcriptional pathways, chronicity of the injury, anatomic location of injury, microenvironmental influences, and the severity of nerve involvement. Elucidating the complex interactions of these factors will provide potential targets for therapeutic intervention in vivo.
\end{abstract}

Keywords Rotator cuff $\cdot$ Fibro-adipogenic progenitors $\cdot$ Fibro-adipogenesis $\cdot$ Muscle regeneration $\cdot$ Beige adipose tissue

\section{Introduction}

Fibro-adipogenic progenitors (FAPs) were first characterized in 2010 by their response to acute muscle injury (1). In mouse models featuring chemically stimulated injuries with notexin (NTX), FAPs were found to proliferate rapidly following

This article is part of the Topical Collection on Fibroadipogenic Progenitors

Ajith K. Subhash

ASubhash@mednet.ucla.edu

1 Department of Orthopaedic Surgery, David Geffen School of Medicine at the University of California Los Angeles, 885 Tiverton Drive, Los Angeles, CA 90095, USA

2 Department of Orthopaedic Surgery, University of California San Francisco, San Francisco, CA, USA

3 USC Epstein Family Center for Sports Medicine at Keck Medicine of USC, Los Angeles, CA, USA injury, with a return to baseline numbers by $4-5$ days following injury (1). In direct injuries resulting from either cardiotoxin (CTX) or glycerol injections, it was found that glycerol but not CTX promoted adipogenic differentiation of FAPs following injection, suggesting the importance of the injury environment on FAP differentiation in the acute setting (2). In another mouse model study, inhibitors of $\alpha \mathrm{v}$ integrins attenuated fibrosis in both skeletal and cardiac muscle suggesting the role of complex molecular pathways and interplay in regulating these processes (3).

In addition to mediating degenerative changes, FAPs have been found to play an important role in stimulating muscle regeneration. Following NTX-mediated injury in mice, transient fibrotic deposition by FAPs was found to be important for normal muscle regeneration, as blockade of FAP proliferation with the TGF- $\beta 1$ antagonist Nilotinib was found to result in decreased myofiber size after injury (4). Wosczyna et al. further demonstrated that depletion of FAPs within regenerating muscle resulted in loss of both muscle stem cells and $\mathrm{CD}_{4} 5^{+}$cell expansion, and impaired muscle regeneration 
(5). Subpopulation analysis of FAPs has identified cellular subtypes that may display a disposition towards a "pro-regenerative" phenotype over an adipogenic phenotype. Yao et al. found that $\mathrm{Gli1}^{+}$FAPs expanded preferentially following NTX injury and promoted the regeneration of myofibers via Hedgehog (Hh) signaling (6). Another study found that type 2 innate immunity signals including IL-4 and IL-13 appear to be important for FAP-supported myogenesis while inhibiting adipogenesis (7).

This healing processing following acute muscle injury contrasts with that of chronic injury states. Prolonged inflammatory signaling within injured skeletal muscle has been shown to promote sustained FAP population expansion and increased fibro/adipogenic differentiation. Another study demonstrated that while TNF-a is a cytokine expressed in the setting of acute, direct muscle injuries, prolonged TGF- $\beta$ signaling prevents apoptosis of FAPs, eventually leading to increased fibrosis and fatty infiltration (FI) (8). Chronic inflammation and sustained activation of the canonical TGF- $\beta$ signaling pathway is a finding common to many inflammatory myopathies and degenerative processes, including muscular dystrophy and amyotrophic lateral sclerosis (ALS) (9-11).

In recent years, the use of advanced sequencing techniques along with single cell biology has solidified a foundational understanding of the defining characteristics of this injuryinduced remodeling process. In addition, the type of injury is a significant determinant in muscle remodeling and progenitor fate. Also, FI of muscle tissue has been identified as a significant pathologic process following injury, specifically in the rotator cuff as compared to other muscles (12). The purpose of this review is to highlight progenitor cells, their contribution to fibro-adipogenesis in rotator cuff tissue, and the factors influencing fibro-adipogenesis in this tissue.

\section{Identification of Muscle Fibro-adipogenic Progenitor Cells}

Fatty degeneration of chronically injured muscle has long been considered the product of activated multipotent progenitor cells in response to muscle injury and defect (13). It was first believed that fibroblasts and adipocytes generated in this process arose from muscle-resident mesenchymal stem cells with myogenic potential, and thus shared a common progenitor with myoblasts seen in muscle regeneration (13). Seeking to further elucidate the true origin of myogenic, fibrogenic, and adipogenic cells observed following muscle injury, Joe et al. determined that among $\mathrm{CD} 45^{-}$(non-hematopoetic)/ $\mathrm{CD} 31^{-}$(non-endothelial) muscle-resident cells, Sca- $1^{-} / \alpha 7$ integrin $^{+}$cell subset were myogenic, while Sca- $1^{+} / \alpha 7$ integrin $^{-}$cells gave rise to both fibroblasts and adipocytes in vitro (1). They also demonstrated that non-myogenic Sca$1^{+} / \alpha 7$-integrin ${ }^{-}$subset uniformly expressed platelet-derived growth factor receptor- $\alpha$ (PDGFR $\alpha$ ), whose constitutive expression was known to drive systemic multi-organ and skeletal muscle fibrosis, and that $98 \%$ of PDGFR $\alpha^{+}$cells in damaged muscle were Sca- $1^{+} / \alpha 7^{-}$, providing a critical link in the cellular origin for the fibrosis and adipogenesis that drive fatty degeneration (1).

Contemporaneously, Uezumi et al. also investigated the role of muscle-resident PDGFR $\alpha^{+}$cells in muscle injury and regeneration, and definitively demonstrated that these cells gave rise to collagen type-I producing cells as well as adipocytes, both in vitro and in vivo (14-16). A follow-up study validated the fibro-adipogenic potential of PDGFR $\alpha^{+}$cells in human skeletal muscle, and found an accumulation of these cells around ectopic fat in the muscles of patients with Duchenne muscular dystrophy, and in fatty and fibrous tissue seen in Volkmann's contractures (2). Believed to represent the same muscle-resident progenitor cells, the $\mathrm{Sca}-1^{+} / \alpha 7$ integrin $^{-}$subset identified in mice by Joe et al., and the PDGFR $\alpha^{+}$cells characterized in mice and humans by Uezemi et al. have become known as FAPs (16). Uezumi et al. further describes that FAPs represent progenitor cells of mesenchymal origin residing in the skeletal muscle stroma, and that they play a critical role in skeletal muscle homeostasis, regeneration, and aberrant fatty degeneration (16).

There is variation in these FAPs ontogeny as well that may contribute to their progenitor potential. FAPs isolated from different anatomical locations may additionally differ in their developmental origins. Lemos et al. characterized a neural crest-derived FAP (NCFAPs) and a mesenchymal tissuederived FAP (MFAPs) (17). Anatomical distribution differed as NCFAPS comprised $30-100 \%$ of the FAP population of axially located mouse masseter (MFAPS comprised remaining percentage) but were not found in the tibialis anterior; rather, MFAPS made up $100 \%$ of the population at that site (17). While both populations exhibited similar ability to contribute to FI, NCFAPS underwent asymmetric proliferation upon myotoxin-induced injury to the masseter, compared to the MFAPs (17). Lee et al. suggest that given the rotator cuff's proximity to the masseter, it may possess a similar NCFAP:MFAP ratio, though further study is needed (18).

\section{Contribution of RC FAPs to Fibro-adipogenesis}

In chronically injured rotator cuff muscle, fibrosis is accompanied by massive fatty degeneration, a pathophysiological change that is unique to the rotator cuff muscle and rarely seen in other muscle groups (19). Several studies indicate that FAPs are a key mediator of the FI that is notably prevalent in rotator cuff injury $(14,20)$. Barry et al. have previously found substantial FI in cuff tear patients versus healthy patients (21). Muscle FI and atrophy are independent predictors 
of worse pain and function following rotator cuff repair surgery (21-24). At this time, rotator cuff FI is considered an irreversible problem $(22,25)$. Given their complex role in muscle regeneration and prominent role in rotator cuff pathology, the rotator cuff population of FAPs have been of special research interest.

Recent studies have implicated PDGFR $\alpha^{+}$FAPs in fibroadipogenesis following massive rotator cuff tears (20, 26-31). Liu et al. demonstrated significant co-localization of immunofluorescence signals from transgenic murine PDGFR $\alpha^{+}$cells and adipogenic markers including peroxisome proliferatoractivated receptor $\gamma(\operatorname{PPAR} \gamma)$, adiponectin, and perilipin A following tendon transection plus denervation in a murine rotator cuff tear (RCT) model (20). Another group reported that proliferation of PDGFR $\alpha^{+}$cells precedes adipogenesis and appearance of adipogenic transcription factors in the same RCT model, indicating that the expansion of PDGFR $\alpha^{+}$FAPs is related to adipogenesis following injury (27). Furthermore, pharmacologic inhibition of PDGFR $\alpha^{+}$via imatinib significantly suppressed adipocyte formation, though the definitive relationship between PDGFR $\alpha^{+}$cells and adipocytes has not been fully identified (27). Mammalian target of rapamycin (mTOR) signaling via sterol regulatory element-binding protein 1 (SREBP-1) and PPARy has been implicated in adipogenesis following RCT, but these studies were conducted in whole muscle samples rather than PDGFR $\alpha^{+}$subpopulations, underscoring the need for further research into the molecular mechanisms by which PDGFR $\alpha^{+}$FAPs promote adipogenesis (32-34).

FAPs also serve as a chief mediator of fibrosis in injured muscle $(16,35)$. Dulauroy et al. identified an ADAM $12^{+} /$ PDGFR $\alpha^{+}$subset of FAPs induced by muscle injury to rapidly proliferate and give rise to fibrogenic progeny in fibrotic regions of injured muscle in a murine cardiotoxin injury model (36). The transforming growth factor $\beta$ (TGF- $\beta$ ) pathway in particular has been implicated as a potent regulator of FAP fibrotic activity, with TGF- $\beta$ addition directly increasing FAP collagen type-I synthesis and expression of genes associated with fibrosis, including $\alpha$-smooth muscle actin ( $\alpha$-SMA) (14-16).

Davies et al. highlighted the distinctive histologic and molecular profiles of FI in the rotator cuff of a rodent model, finding that the supraspinatus developed significantly more FI compared to the gastrocnemius (19). These histological findings correlated with increased expression of TGF- $\beta 1$, pSMAD-2, and the adipogenic transcription factors PPAR $\gamma$ and SREBP-1 in the cuff compared to the hindlimb (19). Another study noted a similar increase in FI between the supraspinatus compared to the tibialis anterior (TA) at 2 weeks following a glycerol injection (18). When comparing the quantity of FAPs present in seven uninjured muscle groups, Lee et al. found that the supraspinatus and infraspinatus contained the highest percentage of FAPs when sorted using flow cytometry, significantly higher than triceps, gastrocnemius, and TA. FAPs from the supraspinatus were additionally found to exhibit significantly higher proliferative potential and form nearly seven times more adipocytes in vitro compared to those from the TA (18). Taken together, it is likely that FAP number in conjunction with increased proliferation and adipogenic differentiation rates in the rotator cuff contribute to the high clinical prevalence of FI in chronic rotator cuff injuries. Their developmental timelines, alterations with repair, variability with age, and interactions with other muscle stem cells, continue to be investigated $(22,24,25,37-40 \bullet \bullet)$.

The potential influence of muscle fiber type found in stabilizing versus locomotive muscles may additionally contribute to the unique phenotypic and genotypic expressions seen in FAPs isolated from the rotator cuff muscles. Observing changes in distribution of type 1 slow-twitch and type II fast-twitch fibers, a rat rotator cuff injury resulted in a persistent shift towards fast-twitch fibers in the superficial portion of the supraspinatus, but a transient shift in the deeper region (41). Histological studies of rat gastrocnemius displayed 95\% fast-twitch fibers (42). Conversely, cadaveric human rotator cuff muscles demonstrated mixed distribution with 54\% type 1 fibers in the supraspinatus (43). These difference in muscle architecture, in addition to other factors such as vascularity (44), may create environments that selectively favor FAPs and drive cell differentiation.

Recently, additional PDGFR $\alpha^{+}$FAP subsets, such as PDGFR $\alpha^{+} /$PDGFR $\beta^{+}$FAPs, have been characterized (29••, $30)$. Jensen et al. demonstrated that these "double positive" FAPs localize to fibrotic and adipogenic tissue following murine RCTs and are highly adipogenic and significantly more fibrogenic than PDGFR $\alpha^{+} /$PDGFR $\beta^{-}$FAPs. Another study found that human muscle-derived PDGFR $\alpha^{+} /$PDGFR $\beta^{+}$ FAPs significantly contributed to adipogenesis and fibrosis following transplantation into chronically injured murine RC muscle, whereas administration of non-fibro-adipogenic, PDGFR $\beta^{+}$PDGFR $\alpha^{-}$human embryonic stem cell attenuated muscle atrophy and fibrosis (30). Taken together, these studies illustrate the multifactorial regenerative capacity of FAPs and the need for further research to elucidate the exact cues and roles of various FAP subsets.

To this end, advances in single-cell RNA sequencing (scRNA-seq) may help characterize specific FAP trajectories based on their transcriptomic profiles $(10,45,46)$. Using scRNA-seq, Malecova et al. identified a subpopulation of pro-fibrotic FAPs expressing vascular cell adhesion molecule 1 (Vcam-1) which may progressively acquire a pro-fibrotic phenotype during the post-injury regeneration process, suggesting the existence of dynamic temporal control of FAP subpopulation activity (10). Interestingly, $\mathrm{Vcam} 1^{+} \mathrm{FAPs}$ from murine $m d x$ dystrophic muscle expressed different genes than Vcam $1^{+}$FAPs from acutely (notexin) injured muscle, further implying dynamic regulatory control of FAP activity based on 
the disease-specific regenerative milieu. Another group also reported heterogeneous FAP activity following acute injury using sc-RNA-seq (46). They identified two distinct FAP subpopulations in resting, non-injured muscle characterized by CXCL14 and DPP4 expression, respectively, and found that at 21 days post-injury, these subpopulations have distinctly different gene expression profiles. De Micheli et al.'s scRNA-seq study of PDGFR $\alpha^{+}$FAPs revealed a temporally dynamic expression pattern of extracellular matrix (ECM)-related genes and chemokines attracting immune cells at different time-points post-injury, reflecting different stages of healing and remodeling (45). Increased expression of chemokines CXCL5 and CXCL11 further supports potential immune cell cross-talk involved in post-injury FAP activation, though further studies in other injury types, including in chronic muscle injury models, are warranted.

Additionally, lineage tracing of myofibroblasts has demonstrated a strong contribution of $\alpha$-SMA ${ }^{\text {lin }}$ cells to scar tissue within an acute RCT murine model (47). These mesenchymal marker cells had an abundant population only following full detachment and repair injury of the rotator cuff and not in a partial tear model. This marker only partially accounts for rotator cuff muscle scarring if the location is situated close to a large vascular supply but is a poor marker for scars located peripheral to interstitial spaces. Another murine model for RCT demonstrated increased gallium-labeled fibroblast activation protein alpha inhibitor uptake following injury up until 14 days (48). These findings are consistent with other studies and suggest that fibroblasts have increased activity during the initial inflammatory phase and aid in rotator cuff repair in the previously mentioned study.

Studies of FAPs in the murine and human RC have identified a variety of potential therapeutic targets with the goal of reducing FI and fibrosis of the rotator cuff. The TGF- $\beta 1$ pathway has been targeted by small molecule inhibitor SB431542, a potent inhibitor of activin receptor-like kinase, in a mouse model of RCT resulting in reduced muscle FI and fibrosis, and correlated with an increase in FAP apoptosis in the setting of TGF- $\beta 1$ blockade (26). Other studies have demonstrated upregulation of TGF- $\beta$ alongside bone morphogenic protein (BMP)-7 and BMP-14 signaling, and other pro-fibrotic genes following injury in animal RCT models $(49,50)$. The antifibrotic, $\alpha \mathrm{v}$ integrin-inhibitor compound, CWHM-12, markedly reduced collagen expression of mouse RC PDGFR- $\beta^{+}$ PDGFR $-\alpha^{+}$FAPs, further suggesting that these cells can be manipulated for therapeutic benefit (29••). FAPs lacking PDGFR- $\alpha$ and those with PDGFR- $\alpha$ therapeutically silenced have additionally shown reduced fibro-adipogenic behavior $(27,29 \bullet \bullet)$. With PDGFR $\alpha$ possibly acting as the key to fibro-adipogenic FAP activity, inhibiting its expression may prove to be an effective strategy to retain the positive role of FAPs while reducing their negative effects (51). Other studies have found that epigenetic factors guide beneficial FAP behavior. Histone deacetylase play a crucial role in the muscle stem cell differentiation, balancing gene expression and repression (52). The use of histone deacetylase inhibitors (HDACi), such as Trichostatin A, has proved useful in reducing muscle atrophy by repressing FAP fibro-adipogenic genes while enhancing FAP's ability to promote differentiation in consort with satellite cells (53).

\section{Beige Adipose Tissue: a Latent Regenerative Phenotype of FAPs}

Brown adipose tissue arises from a distinct lineage and are uniquely characterized by densely packed mitochondria and multilocular lipid droplets with expression of uncoupling protein 1 (UCP-1) (54). This brown-fat-specific protein increases the conductance of protons across the inner mitochondrial membrane, resulting in increased oxygen consumption and heat production (55). The adipocytes derived from FAP cells exhibit a unique ability to preferentially express UCP-1 (28). Under specific stimulation, FAP cells demonstrate this brownlike phenotype and differentiate into a distinct cellular intermediate known as beige adipose tissue (also known as "brite" or "recruitable brown" cells) (56-58). This process is termed "browning" of white fat and produces beige cells that exhibit uncoupled respiration that is equivalent to, and possibly greater than, that of classical brown fat cells (58). The mechanism and timeline by which this browning event occurs remain a focus of research. While some suggest de novo adipogenesis from FAPs, others suggest that white adipose tissue is capable of conversion to beige and vice versa. Evidence also indicates that beige cells can exist in a dormant state with low UCP-1 expression but switch to an active state in response to stimulus $(59,60)$. While these mechanisms remain under investigation, beige cells are recognized as cells with distinct molecular features and a unique genetic profile (58).

While brown adipose tissue is found primarily in infants and certain non-human adult mammals, beige adipose tissue has been identified in perimuscular regions within adult humans. Meyer et al. identified the epimuscular fat of the healthy human RC as a depot for UCP-1 expressing BAT (57). When isolated and co-cultured with skeletal muscle progenitors in a myogenic induction medium, these cells were able to form significantly greater myotubules; this result was seen with BAT from both healthy and torn rotator cuff patients (57). This study added to the expanding literature describing the presence of beige cells in humans.

There is evidence to suggest that FAPs remain as the primary precursor to BAT in skeletal muscle injury. Feeley et al. performed a novel exploration of FAP proliferation in human rotator cuff patients of partial and full-thickness tears (61). As seen in previous animal models, they found significant FAP proliferation to RC injury with the capability to differentiate 
into beige-fat in vitro, visualized by UCP-1 expression; tear size was positively correlated to FAP population size and proliferative potential. Additionally, genetic markers (PRDM16) and pro-myogenic gene expression (follistatin and insulin-like growth factor 1) were upregulated. The authors explain that the functional purpose of FAPs is still under intense investigation; however, their presence in skeletal muscle pathology may indicate the presence of a resident stem cell population that could aid in muscle regeneration under the proper stimulus. One study found that HDACi treatment in a murine RCT model reduced FAP fibro-adipogenic activity while promoting differentiation into brown/beige adipose tissue (BAT), a metabolically active alternative to energy-storing white adipose tissue (62).

With the FAP response established in human RC injury, successful efforts have been made to harness the beneficial role of FAPs for therapeutic intervention. In a murine RCT injury model, UCP-1+ "beige" FAP transplantation by sterile injection resulted in improved muscle fiber size, vascularity, and gait function, with reduced atrophy, fibrosis, and FI, after 6 weeks (63). Lee et al. also illustrated similar results in a delayed rotator cuff repair model (31). In both studies, the transplanted cells maintained their beige phenotype and were visualized adjacent to intramuscular fat 6 weeks after injection. Additionally, the FAP response has been successfully altered in vivo by the use of a selective $\beta 3$-adrenergic receptor agonist, Amibegron. Wang et al. showed that when administered immediately after tendon transection or at the time of delayed tendon repair, Amibegron resulted in significantly increased UCP-1 expression, indicative of white fat browning; clinically, this resulted in reduced muscle atrophy and FI with improved gait (64). When delivered 6 weeks after injury, Amibegron reversed muscle atrophy and FI, challenging the present understanding of FI as irreversible (65). In each of these studies, UCP-1-knockout mice did not exhibit the therapeutic benefit, suggesting that Amibegron's action on FAP is through a UCP 1-dependent mechanism (64). Overall, these studies deliver promise in the potential to manipulate beige FAPs to optimize treatment for muscle injuries such as RCT where muscle regeneration would lead to improved outcomes.

\section{Factors Affecting/Influencing FAP-Mediated Degeneration of Rotator Cuff}

Clinically, different muscles have varying levels of fibroadipogenesis following musculotendinous injury. In particular, the RC has relatively high rates of fibro-adipogenesis following massive chronic rotator cuff tears compared to other muscle groups. This FI and fibrosis of the rotator cuff muscle makes surgical repair of rotator cuff tendons difficult or, at times, impossible, and has encouraged the study of FAPs as previously discussed.
One hypothesis to account for this phenomenon is that differences in FAP distribution and concentration result in the different rates of post-injury fibro-adipogenesis seen in various muscles. To determine if the relative density of FAPs may relate to this clinical phenomenon, one group quantified the density of FAPs in different muscle groups from PDGFRa-eGFP FAP reporter mice. They found that supraspinatus and infraspinatus muscles (17.5\% and 15.7\%) had much higher densities of FAPs than other muscle groups (triceps $5.5 \%$, gastrocnemius $3.5 \%$, tibialis anterior $5.3 \%$ ) on FACS cell sorting (18). Additionally, FAPs isolated from rotator cuff tissue exhibited greater in vitro fibro-adipogenic potency than FAPs isolated from other muscle tissues (18). These findings suggest that the pre-injury density of FAPs in muscle tissue may affect post-injury levels of fibro-adipogenesis, and that FAPs from certain muscle tissue may be more predisposed to post-injury pathologic fibro-adipogenesis than others.

Unfortunately, less is known about the about distribution of FAPs in healthy human muscle tissue due to ethical and methodological limitations, though researchers are investigating new ways of answering this question (66). Interestingly, certain patient populations seem to have increased concentrations of FAPs, such as inherited myopathies including Duchenne Muscular Dystrophy (67). Additionally, type 2 diabetes, obesity, and metabolic syndrome have been associated with increased FAP cell proliferation and dysregulation though not necessarily increased concentration of FAP cells $(68,69)$. Therefore, FAP populations may vary significantly from individual to individual and this may account for some of the heterogeneity seen clinically in tissue response to similar injuries.

Age also has been demonstrated to play a role in FAPs response to muscle injury. One study assessed age-related muscle degeneration following RCT and demonstrated a similar frequency of FAPs in young and old mice, but an increased fibrotic response to muscle injury in aged mice $(40 \bullet \bullet)$. Further studies utilizing older mice are needed to recapitulate the clinical condition following RCT more closely and subsequent chronic fatty degeneration.

Lastly, chronicity of a musculotendinous injury appears to affect FAP population concentration as well. Intraoperative paraspinal muscle (multifidus) biopsies taken for human patients during spinal surgery with acute $(<6$-month duration) or chronic ( $>6$-month duration) pathologies were obtained to compare the different distributions of FAP cells. Significant differences in the makeup of residential cell populations between the two groups were seen. In particular, researchers found that there were more FAP cells in muscle tissue from patients with acute pathology (49.7\%) than in tissue from those with chronic pathology (28.9\%) (70). This suggests that the chronicity of injury affects FAP cell distribution, as well as muscle location and patient variables. 
Similarly, Wu et al. demonstrated that the time after injury also played a key role in rotator cuff remodeling. Early injury demonstrates significant fibrotic activity in the supraspinatus and infraspinatus while the muscle's response to injury at 6 weeks is later dominated by FI (71).

In addition to the density and distribution of FAPs, the local tissue environment appears to play an important role in maintaining tissue homeostasis and inducing pathologic fibro-adipogenic differentiation $(68,72)$. One of the contributing factors to the local tissue environment is innervation, and therefore researchers have examined the contribution of nerve injury to fibroadipogenesis following muscle injury.

In a rat model of rotator cuff tears, researchers have found that suprascapular nerve (SSN) injury leads to worse, histologic, and biomechanical properties and lower healing rates of rotator cuff repairs $(73,74)$. Additionally, SSN compression in a mouse has been shown to lead to increased FI of the supraspinatus muscle, but this is reversible following release of nerve compression (75••). FAP cell dysregulation has also been found in type 2 diabetes, which is associated with peripheral neuropathy, as well as worse outcomes following rotator cuff repairs $(68,69)$.

Denervation appears to affect the local tissue milleu and the complex signaling pathways that influence FAP cell differentiation. In a mouse model of denervation, researchers found that certain transcription factors such as CTGF/CCN2 (at 2-4 days) and TGF- $\beta$ (at 1-2 weeks) were upregulated in hindlimb muscle tissue following sciatic nerve injury. These factors led to the downregulation of extracellular matrix proteins without a change in FAP cell concentration per se (76). They summarized that multiple transcription factors are involved in skeletal muscle pathologic fibrosis following denervation injury. In a separate study using a mouse model of sciatic nerve injury, researchers found that FAPs from denervated muscle tissue, as compared to those from cytotoxin-injured tissue, demonstrated a reduced ability of co-cultured myoblasts to fuse into myotubes, indicating a reduced regenerative potential for FAPs following denervation injury (77). As previously discussed, denervation-activated FAPs exhibited persistent STAT3 activation and secreted elevated levels of IL-6, which promoted muscle atrophy and fibrosis.

Neurodegenerative diseases including ALS and spinal muscular atrophy (SMA) have also been shown to involve pathologic activation of FAPs following muscle denervation. In the denervated muscle within these disease states, FAPs have been found to exhibit pathologic STAT3 activation, which leads to sustained IL-6 secretion by FAPs, ultimately contributing to muscle atrophy and fibrosis through a reciprocal positive feedback loop (77).

\section{Conclusions}

In conclusion, the fibro-adipogenic response to acute and chronic injury in rotator cuff tissue is determined by a complex array of factors including progenitor cell influence, transcriptional pathways, chronicity of the injury, anatomic location of injury, microenvironmental influences, and the severity of nerve involvement. Specifically, it will be important to continue to investigate the transcriptomics and proteomics of each of these processes in order to further characterize skeletal muscle and musculotendinous injury in the rotator cuff. Elucidating the complex interactions of these factors will provide potential targets for therapeutic intervention in vivo.

Declarations This article does not contain any studies with human or animal subjects performed by any of the authors.

Open Access This article is licensed under a Creative Commons Attribution 4.0 International License, which permits use, sharing, adaptation, distribution and reproduction in any medium or format, as long as you give appropriate credit to the original author(s) and the source, provide a link to the Creative Commons licence, and indicate if changes were made. The images or other third party material in this article are included in the article's Creative Commons licence, unless indicated otherwise in a credit line to the material. If material is not included in the article's Creative Commons licence and your intended use is not permitted by statutory regulation or exceeds the permitted use, you will need to obtain permission directly from the copyright holder. To view a copy of this licence, visit http://creativecommons.org/licenses/by/4.0/.

\section{References}

Papers of particular interest, published recently, have been highlighted as:

- Of importance

•- Of major importance

1. Joe AWB, Yi L, Natarajan A, Le Grand F, So L, Wang J, et al. Muscle injury activates resident fibro/adipogenic progenitors that facilitate myogenesis. Nat Cell Biol. 2010 Feb;12(2):153-63.

2. Uezumi A, Fukada S, Yamamoto N, Ikemoto-Uezumi M, Nakatani M, Morita M, Yamaguchi A, Yamada H, Nishino I, Hamada Y, Tsuchida K. Identification and characterization of PDGFR $\alpha+$ mesenchymal progenitors in human skeletal muscle. Cell Death Dis. 2014 Apr;5(4):e1186.

3. Murray IR, Gonzalez ZN, Baily J, Dobie R, Wallace RJ, Mackinnon AC, et al. $\alpha \mathrm{v}$ integrins on mesenchymal cells regulate skeletal and cardiac muscle fibrosis. Nat Commun. 2017;8(1): 1118.

4. Fiore D, Judson RN, Low M, Lee S, Zhang E, Hopkins C, Xu P, Lenzi A, Rossi FMV, Lemos DR. Pharmacological blockage of fibro/adipogenic progenitor expansion and suppression of regenerative fibrogenesis is associated with impaired skeletal muscle regeneration. Stem Cell Res. 2016 Jul;17(1):161-9.

5. Wosczyna MN, Konishi CT, Perez Carbajal EE, Wang TT, Walsh RA, Gan Q, et al. Mesenchymal stromal cells are required for 
regeneration and homeostatic maintenance of skeletal muscle. Cell Rep. 2019;27(7):2029-2035.e5.

6. Yao L, Tichy ED, Zhong L, Mohanty S, Wang L, Ai E, Yang S, Mourkioti F, Qin L. Gli1 defines a subset of fibro-adipogenic progenitors that promote skeletal muscle regeneration with less fat accumulation. J bone Miner Res Off J Am Soc Bone Miner Res. 2021 Jun;36(6):1159-73.

7. Heredia JE, Mukundan L, Chen FM, Mueller AA, Deo RC, Locksley RM, Rando TA, Chawla A. Type 2 innate signals stimulate fibro/adipogenic progenitors to facilitate muscle regeneration. Cell. 2013 Apr;153(2):376-88.

8. Lemos DR, Babaeijandaghi F, Low M, Chang C-K, Lee ST, Fiore D, Zhang RH, Natarajan A, Nedospasov SA, Rossi FMV. Nilotinib reduces muscle fibrosis in chronic muscle injury by promoting TNF-mediated apoptosis of fibro/adipogenic progenitors. Nat Med. 2015 Jul;21(7):786-94.

9. Gonzalez D, Contreras O, Rebolledo DL, Espinoza JP, van Zundert B, Brandan E. ALS skeletal muscle shows enhanced TGF- $\beta$ signaling, fibrosis and induction of fibro/adipogenic progenitor markers. PLoS One. 2017;12(5):e0177649.

10. Malecova B, Gatto S, Etxaniz U, Passafaro M, Cortez A, Nicoletti C, Giordani L, Torcinaro A, de Bardi M, Bicciato S, de Santa F, Madaro L, Puri PL. Dynamics of cellular states of fibro-adipogenic progenitors during myogenesis and muscular dystrophy. Nat Commun. 2018 Sep;9(1):3670.

11. Moratal C, Arrighi N, Dechesne CA, Dani C. Control of muscle fibro-adipogenic progenitors by myogenic lineage is altered in aging and Duchenne muscular dystrophy. Cell Physiol Biochem Int J Exp Cell Physiol Biochem Pharmacol. 2019;53(6):1029-45.

12. Melis B, Nemoz C, Walch G. Muscle fatty infiltration in rotator cuff tears: descriptive analysis of 1688 cases. Orthop Traumatol Surg Res. 2009 Sep;95(5):319-24.

13. Frey E, Regenfelder F, Sussmann P, Zumstein M, Gerber C, Born $\mathrm{W}$, Fuchs B. Adipogenic and myogenic gene expression in rotator cuff muscle of the sheep after tendon tear. J Orthop Res Off Publ Orthop Res Soc. 2009 Apr;27(4):504-9.

14. Uezumi A, Ito T, Morikawa D, Shimizu N, Yoneda T, Segawa M, Yamaguchi M, Ogawa R, Matev MM, Miyagoe-Suzuki Y, Takeda S', Tsujikawa K, Tsuchida K, Yamamoto H, Fukada SI. Fibrosis and adipogenesis originate from a common mesenchymal progenitor in skeletal muscle. J Cell Sci. 2011 Nov;124(Pt 21):3654-64.

15. Uezumi A, Fukada S, Yamamoto N, Takeda S, Tsuchida K. Mesenchymal progenitors distinct from satellite cells contribute to ectopic fat cell formation in skeletal muscle. Nat Cell Biol. 2010 Feb;12(2):143-52.

16. Uezumi A, Ikemoto-Uezumi M, Tsuchida K. Roles of nonmyogenic mesenchymal progenitors in pathogenesis and regeneration of skeletal muscle. Front Physiol. 2014;5:68.

17. Lemos DR, Paylor B, Chang C, Sampaio A, Underhill TM, Rossi FMV. Functionally convergent white adipogenic progenitors of different lineages participate in a diffused system supporting tissue regeneration. Stem Cells. 2012 Jun;30(6):1152-62.

18. Lee C, Agha O, Liu M, Davies M, Bertoy L, Kim HT, Liu X, Feeley BT. Rotator cuff fibro-adipogenic progenitors demonstrate highest concentration, proliferative capacity, and adipogenic potential across muscle groups. J Orthop Res Off Publ Orthop Res Soc. 2020 May;38(5):1113-21.

19. Davies MR, Ravishankar B, Laron D, Kim HT, Liu X, Feeley BT. Rat rotator cuff muscle responds differently from hindlimb muscle to a combined tendon-nerve injury. J Orthop Res Off Publ Orthop Res Soc. 2015 Jul;33(7):1046-53.

20. Liu X, Ning AY, Chang NC, Kim H, Nissenson R, Wang L, Feeley BT. Investigating the cellular origin of rotator cuff muscle fatty infiltration and fibrosis after injury. Muscles Ligaments Tendons J. 2016;6(1):6-15.
21. Barry JJ, Lansdown DA, Cheung S, Feeley BT, Ma CB. The relationship between tear severity, fatty infiltration, and muscle atrophy in the supraspinatus. J shoulder Elb Surg. 2013 Jan;22(1):18-25.

22. Gladstone JN, Bishop JY, Lo IKY, Flatow EL. Fatty infiltration and atrophy of the rotator cuff do not improve after rotator cuff repair and correlate with poor functional outcome. Am J Sports Med. 2007 May;35(5):719-28.

23. Jain NB, Ayers GD, Fan R, Kuhn JE, Baumgarten KM, Matzkin E, Higgins LD. Predictors of pain and functional outcomes after operative treatment for rotator cuff tears. J shoulder Elb Surg. 2018 Aug;27(8):1393-400.

24. Shen P-H, Lien S-B, Shen H-C, Lee C-H, Wu S-S, Lin L-C. Longterm functional outcomes after repair of rotator cuff tears correlated with atrophy of the supraspinatus muscles on magnetic resonance images. J shoulder Elb Surg. 2008;17(1 Suppl):1S-7S.

25. Lansdown DA, Lee S, Sam C, Krug R, Feeley BT, Ma CB. A prospective, quantitative evaluation of fatty infiltration before and after rotator cuff repair. Orthop J Sport Med. 2017 Jul;5(7): 2325967117718537.

26. Davies MR, Liu X, Lee L, Laron D, Ning AY, Kim HT, Feeley BT. TGF- $\beta$ small molecule inhibitor SB431542 reduces rotator cuff muscle fibrosis and fatty infiltration by promoting fibro/ adipogenic progenitor apoptosis. PLoS One. 2016;11(5):e0155486.

27. Shirasawa H, Matsumura N, Shimoda M, Oki S, Yoda M, Tohmonda T, Kanai Y, Matsumoto M, Nakamura M, Horiuchi $\mathrm{K}$. Inhibition of PDGFR signaling prevents muscular fatty infiltration after rotator cuff tear in mice. Sci Rep. 2017 Jan;7:41552.

28. Gorski T, Mathes S, Krützfeldt J. Uncoupling protein 1 expression in adipocytes derived from skeletal muscle fibro/adipogenic progenitors is under genetic and hormonal control. J Cachexia Sarcopenia Muscle. 2018 Apr;9(2):384-99.

29.• Jensen AR, Kelley BV, Mosich GM, Ariniello A, Eliasberg CD, $\mathrm{Vu}$ B, et al. Neer Award 2018: platelet-derived growth factor receptor $\alpha$ co-expression typifies a subset of platelet-derived growth factor receptor $\beta$-positive progenitor cells that contribute to fatty degeneration and fibrosis of the murine rotator cuff. J shoulder Elb Surg. 2018;27(7):1149-61 This study identified a subset of progenitor cells that contributed to fibrosis and fatty degeneration while also identifying that their inhibition could lead to limited rotator cuff tissue degeneration clinically.

30. Mosich GM, Husman R, Shah P, Sharma A, Rezzadeh K, Aderibigbe $\mathrm{T}$, et al. Non-fibro-adipogenic pericytes from human embryonic stem cells attenuate degeneration of the chronically injured mouse muscle. JCI insight. 2019;4(24).

31. Lee C, Liu M, Agha O, Kim HT, Liu X, Feeley BT. Beige fibroadipogenic progenitor transplantation reduces muscle degeneration and improves function in a mouse model of delayed repair of rotator cuff tears. J shoulder Elb Surg. 2020 Apr;29(4):719-27.

32. Liu X, Joshi SK, Samagh SP, Dang Y-X, Laron D, Lovett DH, Bodine SC, Kim HT, Feeley BT. Evaluation of Akt/mTOR activity in muscle atrophy after rotator cuff tears in a rat model. J Orthop Res Off Publ Orthop Res Soc. 2012 Sep;30(9):1440-6.

33. Joshi SK, Liu X, Samagh SP, Lovett DH, Bodine SC, Kim HT, Feeley BT. mTOR regulates fatty infiltration through SREBP-1 and PPAR $\gamma$ after a combined massive rotator cuff tear and suprascapular nerve injury in rats. J Orthop Res Off Publ Orthop Res Soc. 2013 May;31(5):724-30.

34. Gumucio JP, Davis ME, Bradley JR, Stafford PL, Schiffman CJ, Lynch EB, Claflin DR, Bedi A, Mendias CL. Rotator cuff tear reduces muscle fiber specific force production and induces macrophage accumulation and autophagy. J Orthop Res Off Publ Orthop Res Soc. 2012 Dec;30(12):1963-70.

35. Wosczyna MN, Rando TA. A muscle stem cell support group: coordinated cellular responses in muscle regeneration. Dev Cell. 2018 Jul;46(2):135-43. 
36. Dulauroy S, Di Carlo SE, Langa F, Eberl G, Peduto L. Lineage tracing and genetic ablation of ADAM12(+) perivascular cells identify a major source of profibrotic cells during acute tissue injury. Nat Med. 2012 Aug;18(8):1262-70.

37. Biferali B, Proietti D, Mozzetta C, Madaro L. Fibro-adipogenic progenitors cross-talk in skeletal muscle: the social network. Front Physiol. 2019;10:1074.

38. Davies MR, Garcia S, Tamaki S, Liu X, Lee S, Jose A, Pomerantz JH, Feeley BT. Muscle stem cell activation in a mouse model of rotator cuff injury. J Orthop Res Off Publ Orthop Res Soc. 2018 May;36(5):1370-6.

39. Liu X, Manzano G, Kim HT, Feeley BT. A rat model of massive rotator cuff tears. J Orthop Res Off Publ Orthop Res Soc. 2011 Apr;29(4):588-95.

40.• Sharma AK, Levian B, Shah P, Mosich GM, Husman R, Ariniello A, et al. Aged mice demonstrate greater muscle degeneration of chronically injured rotator cuff. J Orthop Res Off Publ Orthop Res Soc. 2020;38(2):320-8 This study suggests that current mouse models for massive rotator cuff tears should use aged mice rather than young mice to more accurately recapitulate the pathology in humans as aged mice have a greater fibroadipogenic response following tears.

41. Barton ER, Gimbel JA, Williams GR, Soslowsky LJ. Rat supraspinatus muscle atrophy after tendon detachment. J Orthop Res Off Publ Orthop Res Soc. 2005 Mar;23(2):259-65.

42. Armstrong RB, Phelps RO. Muscle fiber type composition of the rat hindlimb. Am J Anat. 1984 Nov;171(3):259-72.

43. Lovering RM, Russ DW. Fiber type composition of cadaveric human rotator cuff muscles. J Orthop Sports Phys Ther. 2008 Nov;38(11):674-80.

44. Iwayama T, Steele C, Yao L, Dozmorov MG, Karamichos D, Wren JD, Olson LE. PDGFR $\alpha$ signaling drives adipose tissue fibrosis by targeting progenitor cell plasticity. Genes Dev. 2015 Jun;29(11): 1106-19.

45. De Micheli AJ, Laurilliard EJ, Heinke CL, Ravichandran H, Fraczek P, Soueid-Baumgarten S, et al. Single-cell analysis of the muscle stem cell hierarchy identifies heterotypic communication signals involved in skeletal muscle regeneration. Cell Rep. 2020;30(10):3583-3595.e5.

46. Oprescu SN, Yue F, Qiu J, Brito LF, Kuang S. Temporal dynamics and heterogeneity of cell populations during skeletal muscle regeneration. iScience. 2020;23(4):100993.

47. Moser HL, Abraham AC, Howell K, Laudier D, Zumstein MA, Galatz LM, Huang AH. Cell lineage tracing and functional assessment of supraspinatus tendon healing in an acute repair murine model. J Orthop Res Off Publ Orthop Res Soc. 2021 Aug;39(8): 1789-99.

48. Zhang X, Chen D, Babich JW, Green SJE, Deng X-H, Rodeo SA. In vivo imaging of fibroblast activity using a $68 \mathrm{Ga}$-labeled fibroblast activation protein alpha (FAP- $\alpha$ ) inhibitor: study in a mouse rotator cuff repair model. J Bone Joint Surg Am. 2021 May;103(10):e40.

49. Liu X, Joshi SK, Ravishankar B, Laron D, Kim HT, Feeley BT. Upregulation of transforming growth factor- $\beta$ signaling in a rat model of rotator cuff tears. J shoulder Elb Surg. 2014 Nov;23(11):1709-16.

50. Liu X, Joshi S, Ravishankar B, Laron D, Kim HT, Feeley BT. Bone morphogenetic protein signaling in rotator cuff muscle atrophy and fatty infiltration. Muscles Ligaments Tendons J. 2015;5(2):113-9.

51. Agha O, Diaz A, Davies M, Kim HT, Liu X, Feeley BT. Rotator cuff tear degeneration and the role of fibro-adipogenic progenitors. Ann N Y Acad Sci. 2021 Apr;1490(1):13-28.

52. Sincennes M-C, Brun CE, Rudnicki MA. Concise review: epigenetic regulation of myogenesis in health and disease. Stem Cells Transl Med. 2016 Mar;5(3):282-90.
53. Mozzetta C, Consalvi S, Saccone V, Tierney M, Diamantini A, Mitchell KJ, Marazzi G, Borsellino G, Battistini L, Sassoon D, Sacco A, Puri PL. Fibroadipogenic progenitors mediate the ability of HDAC inhibitors to promote regeneration in dystrophic muscles of young, but not old Mdx mice. EMBO Mol Med. 2013 Apr;5(4): 626-39.

54. Timmons JA, Wennmalm K, Larsson O, Walden TB, Lassmann T, Petrovic N, Hamilton DL, Gimeno RE, Wahlestedt C, Baar K, Nedergaard J, Cannon B. Myogenic gene expression signature establishes that brown and white adipocytes originate from distinct cell lineages. Proc Natl Acad Sci U S A. 2007 Mar;104(11):4401-6.

55. Fedorenko A, Lishko PV, Kirichok Y. Mechanism of fatty-aciddependent UCP1 uncoupling in brown fat mitochondria. Cell. 2012 Oct:151(2):400-13.

56. Bryniarski AR, Meyer GA. Brown fat promotes muscle growth during regeneration. J Orthop Res Off Publ Orthop Res Soc. 2019 Aug;37(8):1817-26.

57. Meyer GA, Gibbons MC, Sato E, Lane JG, Ward SR, Engler AJ. Epimuscular fat in the human rotator cuff is a novel beige depot. Stem Cells Transl Med. 2015 Jul;4(7):764-74.

58. Wu J, Boström P, Sparks LM, Ye L, Choi JH, Giang A-H, Khandekar M, Virtanen KA, Nuutila P, Schaart G, Huang K, Tu H, van Marken Lichtenbelt WD, Hoeks J, Enerbäck S, Schrauwen $\mathrm{P}$, Spiegelman BM. Beige adipocytes are a distinct type of thermogenic fat cell in mouse and human. Cell. 2012 Jul;150(2):366-76.

59. Chechi K, van Marken LW, Richard D. Brown and beige adipose tissues: phenotype and metabolic potential in mice and men. J Appl Physiol. 2018 Feb;124(2):482-96.

60. Harms M, Seale P. Brown and beige fat: development, function and therapeutic potential. Nat Med. 2013 Oct;19(10):1252-63.

61. Feeley BT, Liu M, Ma CB, Agha O, Aung M, Lee C, Liu X. Human rotator cuff tears have an endogenous, inducible stem cell source capable of improving muscle quality and function after rotator cuff repair. Am J Sports Med. 2020 Sep;48(11):2660-8.

62. Liu X, Liu M, Lee L, Davies M, Wang Z, Kim H, Feeley BT. Trichostatin A regulates fibro/adipogenic progenitor adipogenesis epigenetically and reduces rotator cuff muscle fatty infiltration. J Orthop Res Off Publ Orthop Res Soc. 2021 Jul;39(7):1452-62.

63. Lee C, Liu M, Agha O, Kim HT, Feeley BT, Liu X. Beige FAPs transplantation improves muscle quality and shoulder function after massive rotator cuff tears. J Orthop Res Off Publ Orthop Res Soc. 2020 May;38(5):1159-66.

64. Wang Z, Liu X, Jiang K, Kim H, Kajimura S, Feeley BT. Intramuscular brown fat activation decreases muscle atrophy and fatty infiltration and improves gait after delayed rotator cuff repair in mice. Am J Sports Med. 2020 Jun;48(7):1590-600.

65. Wang Z, Liu X, Liu M, Jiang K, Kajimura S, Kim H, Feeley BT. $\beta(3)$-Adrenergic receptor agonist treats rotator cuff fatty infiltration by activating beige fat in mice. J shoulder Elb Surg. 2021 Feb;30(2):373-86.

66. Jensen JB, Møller AB, Just J, Mose M, de Paoli FV, Billeskov TB, et al. Isolation and characterization of muscle stem cells, fibroadipogenic progenitors and macrophages from human skeletal muscle biopsies. Am J Physiol Cell Physiol. 2021.

67. Theret M, Rossi FMV, Contreras O. Evolving roles of muscleresident fibro-adipogenic progenitors in health, regeneration, neuromuscular disorders, and aging. Front Physiol. 2021;12:673404.

68. Teng S, Huang P. The effect of type 2 diabetes mellitus and obesity on muscle progenitor cell function. Stem Cell Res Ther. 2019 Mar;10(1):103.

69. Buras ED, Converso-Baran K, Davis CS, Akama T, Hikage F, Michele DE, Brooks SV, Chun TH. Fibro-adipogenic remodeling of the diaphragm in obesity-associated respiratory dysfunction. Diabetes. 2019 Jan;68(1):45-56.

70. Shahidi B, Gibbons MC, Esparza M, Zlomislic V, Allen RT, Garfin SR, Ward SR. Cell populations and muscle fiber morphology 
associated with acute and chronic muscle degeneration in lumbar spine pathology. JOR spine. 2020 Jun;3(2):e1087.

71. Wu G, Hu VJ, McClintick DJ, Gatto JD, Aderibigbe T, Lu L, et al. Lateral to medial fibro-adipogenic degeneration are greater in infraspinatus than supraspinatus following nerve and tendon injury of murine rotator cuff. J Orthop Res Off Publ Orthop Res Soc. 2021 Jan;39(1):184-95.

72. Santini MP, Malide D, Hoffman G, Pandey G, D'Escamard V, Nomura-Kitabayashi A, et al. Tissue-resident PDGFR $\alpha(+)$ progenitor cells contribute to fibrosis versus healing in a context- and spatiotemporally dependent manner. Cell Rep. 2020;30(2):555570.e7.

73. Sun Y, Kwak J-M, Zhou Y, Fu Y, Wang Z, Chen Q, Jeon IH. Suprascapular nerve injury affects rotator cuff healing: a paired controlled study in a rat model. J Orthop Transl. 2021 Mar;27: 153-60.

74. Akimoto K, Ochiai N, Hashimoto E, Sasaki Y, Nojima D, Kajiwara D, Matsuura Y, Sasaki Y, Yamaguchi T, Kijima T, Ohtori S. Influence of a nerve injury proximal to the suprascapular nerve on healing of repaired rotator cuff tear. J Orthop Sci Off J Japanese Orthop Assoc. 2020 Jan;25(1):96-103.
75.•• Wang Z, Feeley BT, Kim HT, Liu X. Reversal of fatty infiltration after suprascapular nerve compression release is dependent on UCP1 expression in mice. Clin Orthop Relat Res. 2018;476(8): 1665-79 This study identified a potentially novel treatment in reversing rotator cuff muscle fatty infilitration specifically in patients with suprascapular nerve injury.

76. Rebolledo DL, González D, Faundez-Contreras J, Contreras O, Vio CP, Murphy-Ullrich JE, Lipson KE, Brandan E. Denervationinduced skeletal muscle fibrosis is mediated by $\mathrm{CTGF} / \mathrm{CCN} 2$ independently of TGF- $\beta$. Matrix Biol. 2019 Sep;82:20-37.

77. Madaro L, Passafaro M, Sala D, Etxaniz U, Lugarini F, Proietti D, Alfonsi MV, Nicoletti C, Gatto S, de Bardi M, Rojas-García R, Giordani L, Marinelli S, Pagliarini V, Sette C, Sacco A, Puri PL. Denervation-activated STAT3-IL-6 signalling in fibro-adipogenic progenitors promotes myofibres atrophy and fibrosis. Nat Cell Biol. 2018 Aug;20(8):917-27.

Publisher's Note Springer Nature remains neutral with regard to jurisdictional claims in published maps and institutional affiliations. 